\title{
A further study of amino acid analysis and conditioning of planarians ${ }^{\prime, 2}$
}

\author{
F. J. KING, F. T. CRAWFORD AND ROGER L. KLINGAMAN
}

FLORIDA STATE UNIVERSITY

\begin{abstract}
Two groups of planaris regenerated from heads or tails were subdivided into groups in which CS and UCS were either paired or non-paired. After 120 presentations of CS and UCS the animals were subjected to amino acid analysis. Significant behavioral differences were found, but biochemical-behavioral correlations were not significant.
\end{abstract}

\section{Problem}

A previous study on planarians (Crawford, King, \& Siebert, 1965) reported correlations between frequency of conditioned body contraction and certain groups of amino acids. In that study the worms were selected at random, being equated approximately only for size. Greater experimental sensitivity would have been attained if it had been possible to have matched Ss. The present experiment, therefore, attempted to reduce subject variability both behaviorally and biochemically by using regenerated worms in an experiment in which the UCS and CS were either paired or unpaired. By placing one of a regenerated pair in each of the groups they would, to a certain extent, "serve as their own controls."

\section{Method}

Subjects. Twenty-five Dugesia dorotocephala were transected and placed into dual-chambered containers. Chambers were numbered so that worms' original heads or tails could be identified. Ss were regenerated in spring water with the water being changed every three or four days. Following three weeks of regeneration they were fed beef liver. Two more weeks of regeneration were allowed before conditioning was initiated. Regeneration took place under conditions of relative darkness.

Apparatus. A modified version of the apparatus described by McConnell, Cornwell, \& Clay (1960) was employed.

Procedure. Fourteen of the original 25 pairs survived. These Ss were divided into two groups of 14 Ss with 7 heads and 7 tails in each group. The head and the tail of a given $\mathrm{S}$ were placed in different groups. The remaining Ss were discarded.

One group of Ss (Group I) were given 120 presentations of 3 sec. light and 1 sec. shock which were unpaired. Light and shock presentations were separated by $15 \mathrm{sec}$. intervals. Ss in Group II were given 120 paired light and shock presentations of the same duration of $15 \mathrm{sec}$. intervals. The shock presentation coincided with the terminal $1 \mathrm{sec}$. of light. For both groups the occurrence of a body contraction during the initial
2 sec. of light was used as the behavioral response. Trials were always run with a paired head and tail, with right and left troughs counterbalanced. Paired Ss were run at the same time and given the total of 120 trials at one session. Testing for all Ss covered a six day period. Following training each $\mathrm{S}$ was placed on chromatographic paper, allowed to dry, and subjected to an amino acid analysis according to the procedure previously described (Crawford et al, 1965). The chromatographic analyses for two animals were spoiled. Thus, for the statistical analyses of the biochemical results the total $\mathrm{N}$ was reduced to 20 since the other members of each pair had to be discarded and the N's in the unaffected groups reduced to equal size.

\section{Hesults and Diseussion}

The behavioral data were analyzed by a $2 \times 2 \times 5$ repeated measures analysis of variance design. The two levels of the first factor were Group I (unpaired) and Group II (paired). Worms regenerated from heads were in level one of the second factor, and level two contained worms regenerated from tails. Each of the five levels of factor three was composed of 24 trials. Main effects significant beyond the .01 level were found for treatment and blocks of trials, and the treatment by block interaction was significant beyond the .01 level. Thus, the pairing of the UCS and CS produced a progressively greater number of conditioned responses than the unpaired treatment. Section of the animal used for regeneration was not significant nor did it contribute to any interaction effects. However, Fig. 1 shows a tendency for paired "tails" to have higher scores than paired "heads" in every block except possibly the last one.

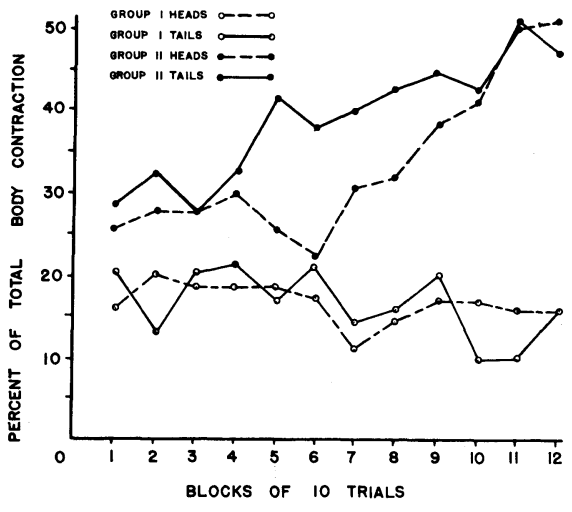

Fig. 1. Percent conditioned responses to light presentation. 
The results of the chromatographic analyses were difficult to interpret. In marked contrast to the uniform results of an earlier analysis (Crawford et al, 1965), the number of spots per worm varied from three to six and their Rf values were highly inconsistent. These difficulties may, however, have been due to a "bad run"; the reduced number of spots per worm have been found in other unpublished analyses of regenerating worms and may indicate altered metabolic composition in worms that appear to be morphologically complete. Two spots on each chromatogram were tentatively identified as being the same as spots 1 and 3 of the previous study. These spots were measures of groups of acids that had been previously found to have significant correlations with the behavioral data. A $2 \times 2$ (treatment $x$ body section) analysis of variance and a $2 \times 10$ (treatment by worm pair) analysis of variance were done on each spot. No significant differences were found. The two amino acid spots were correlated with five blocks of trials. No significant correlations were found but the pattern of change in correlations over the blocks was interesting. For spot 3 the correlations were -,26, -.22, $.22, .23, .30$. For spot 1 a similar pattern appeared.

Failure to find either significant treatment effects for spot three or significant correlations between the biochemical and behavioral data were surprising in view of the positive results of the previous study. The inconsistent chromatographic analyses may have been sufficiently in error to mask any significant finding. An important difference between this study and the previous one was in the duration of time in which the behavioral data were gathered. In the first study (Crawford et al, 1965) the animals were given 8 trials a day for 15 days. In the present study all 120 trials were conducted on the same day. The high degree of massing may have prevented biochemical changes due to learning from being detected in the relatively crude chromatographic analyses, and, as previously stated, biochemical regeneration may have been incomplete.

\section{References}

McConnell, J. v., Cornwell, P. R., \& Clay, Margaret. An apparatus for conditioning planaria. Amer. J. Psychol., 1960, 73, 618-622.

Crawford, F. T., King, F. J., \& Siebert, Lynne.E. Amino acid analysis of planarians following conditioning. Psychon. Sci., $1965,2,49-50$.

\section{Noter}

1. This research was supported in part by a grant from the Florida State University. Research Council.

2. The statistical analyses were made possible in part by NSF Grant (No. GP671) to the Florida State University Computation Center. 